\title{
The Syndrome of Inappropriate Antidiuresis: Pathophysiology, Clinical Management and New Therapeutic Options
}

\author{
Pasquale Esposito Giovanni Piotti Stefania Bianzina Yehuda Malul \\ Antonio Dal Canton
}

Department of Nephrology, Dialysis and Transplantation, Fondazione IRCCS Policlinico San Matteo and University of Pavia, Pavia, Italy

\section{Key Words}

Syndrome of inappropriate antidiuresis - Antidiuretic hormone $\cdot$ Hyponatremia $\cdot$ Nephrogenic syndrome of inappropriate antidiuresis $\cdot$ Vaptans

\begin{abstract}
Hyponatremia is a marker of different underlying diseases and it can be a cause of morbidity itself; this implies the importance of a correct approach to the problem. The syndrome of inappropriate antidiuresis (SIAD) is one of the most common causes of hyponatremia: it is a disorder of sodium and water balance characterized by urinary dilution impairment and hypotonic hyponatremia, in the absence of renal disease or any identifiable non-osmotic stimulus able to induce antidiuretic hormone (ADH) release; according to its definition, it is diagnosed through an exclusion algorithm. SIAD is usually observed in hospitalized patients and its prevalence may be as high as $35 \%$. The understanding of the syndrome has notably evolved over the last years, as reflected by the significant change in the name, once the syndrome of inappropriate secretion of ADH (SIADH), today SIAD. This review is up to date and it analyses the newest notions about pathophysiological mechanisms, classification, management and therapy of SIAD, including vaptans.
\end{abstract}

Copyright $\odot 2011$ S. Karger AG, Basel

\section{KARGER}

Fax +41613061234 E-Mail karger@karger.ch www.karger.com

\section{Introduction}

In the long run, water intake and water loss compensate each other in order to maintain a hydrosaline balance and prevent either dehydration or a hypervolemic state. The homeostasis is finely regulated by hypothalamus, neurohypophysis, kidneys and circulating hormones, the most important of which is the antidiuretic hormone $(\mathrm{ADH})$, also known as arginine vasopressin (AVP).

The 'syndrome of inappropriate secretion of antidiuretic hormone' (SIADH), first described by Schwartz et al. [1] in 2 patients with bronchogenic carcinoma with a lack of the physiological stimulus for the release of $\mathrm{ADH}$, is characterized by inappropriate release of $\mathrm{ADH}$. According to the fact that not all the afflicted patients show elevated circulating levels of ADH, the expression 'syndrome of inappropriate antidiuresis' (SIAD) was proposed as being more accurate [2].

\section{Arginine Vasopressin: Synthesis, Function, Receptors and Mechanisms, Osmotic and Non- Osmotic Stimuli}

$\mathrm{ADH}$ is a 9-amino-acid cyclic peptide with a disulfide bridge between cysteine residues at positions 1 and 6 . It is synthesized in the hypothalamic supraoptic and paraven-

Tel. +39 038250 3883, E-Mail pasqualeesposito@ hotmail.com 
tricular nuclei neurons, then transported along the axons to the posterior lobe of the hypophysis and, in response to a number of stimuli, is released into the circulation [3]. Circulating ADH is rapidly metabolized by hepatic and renal aminopeptidase with a half-time in humans of about $18 \mathrm{~min}$. In particular, vasopressinase, also called oxytocinase or placental leucine aminopeptidase, is a widely expressed type II membrane-spanning protein of the M1 aminopeptidase family, which cleaves S-benzyl-cysteine and inactivates vasopressin (and oxytocin) by releasing its $\mathrm{N}$-terminal cysteine residues. It is expressed as a membrane protein and then secreted into the blood through proteolytic cleavage [4]. The circulating form of vasopressinase could be an important regulator of ADH levels and it is particularly abundant during pregnancy, insomuch as its elevated levels have been proposed as the main cause of gestational diabetes insipidus [5].

Three known receptors bind ADH at the cell membrane: V1a, V1b (also known as V3) and V2. These receptors belong to the G-protein-coupled receptor superfamily. $\mathrm{ADH}$ binding to $\mathrm{V} 1 \mathrm{a}$ and $\mathrm{V} 1 \mathrm{~b}$ receptors results in phospholipase $\mathrm{C}$ activation and elevation of intracellular calcium that, in turn, stimulates protein kinase C. Instead, the binding to $\mathrm{V} 2$ receptors activates adenylate $\mathrm{cy}$ clase, causing a rise in intracellular cyclic adenosine monophosphate (cAMP) [6].

V1a subtype is ubiquitous and it is found on several cells, such as vascular smooth muscle cells, hepatocytes, platelets, brain and uterus cells. This receptor mediates the cardiovascular effects of $\mathrm{ADH}$, which exerts its hypertensive effects mainly through smooth muscle cell contraction [7]. Moreover, the stimulation of V1a receptors regulates glycogenolysis, platelet aggregation, myocyte hypertrophy, anxiety and stress [8]. V1b receptors are found predominantly in the anterior pituitary gland and their stimulation results in the release of adrenocorticotropic hormone (ACTH) [9]. Finally, V2 receptors are found in endothelial cells, where their activation induces the secretion of von Willebrand factor [8], and on the basolateral membrane of the principal cells of the renal collecting ducts, where they mediate an antidiuretic response. Stimulation of V2 receptors, through intracellular cAMP, increases synthesis and insertion of aquaporin-2 (AQP2) water channels in the luminal membrane of the collecting ducts, thus making them permeable to water [10]. Consequently, water passes passively to the hypertonic interstitium of renal pyramids, resulting in urine concentration. $\mathrm{ADH}$ antidiuretic action also depends on its ability of maintaining the medullary interstitial osmotic gradients by increasing the number of ep- ithelial $[\mathrm{Na}+]$ channels $(\mathrm{ENaC})$ and urea transporters (UT-A1), thus enhancing sodium and urea permeability in the collecting duct [11].

ADH secretion is influenced by many different stimuli, which can be classified as osmotic and non-osmotic. Under physiological conditions, the most important stimulus is the effective osmotic pressure of plasma. Osmoreceptors are located in the anterior hypothalamus, outside the hemato-encephalic barrier, mostly on the vascular side of the terminal lamina around the ventricles, exposed to the osmotic variations of the systemic circulation [12]. The threshold for ADH release cessation corresponds to a plasmatic osmolality $<275 \mathrm{mosm} / \mathrm{kg}$, while for plasmatic osmolality of $284 \mathrm{mosm} / \mathrm{kg}$ or higher, $\mathrm{ADH}$ concentration rises linearly. ADH receptors are so sensitive that $1 \%$ osmotic variations are sufficient to determine significant modifications in ADH secretion [13].

Hypovolemia is a potent non-osmotic stimulus for $\mathrm{ADH}$ secretion in humans. Baroreceptors are classified in low- and high-pressure receptors and the activation of both of them results in $\mathrm{ADH}$ increase. The low-pressure receptors are located in larger veins, right and left atrium and lungs, while the high-pressure ones in the carotid sinuses and aortic arch. ECF depletion initially induces secretion of vasopressin through low-pressure receptors pathways, thus working even with normal arterial pressure [14]. Angiotensin II and norepinephrine, which reinforce the response to hypovolemia, further stimulate $\mathrm{ADH}$ secretion [15]. Among the other non-osmotic stimuli, like stress, nausea, vomiting, drugs and hypoglycemia [16], nociceptive stimuli, mainly post-surgery pain, have been clearly associated with an increase in ADH levels, but the underlying mechanism has not been characterized so far [17].

\section{Definition of SIAD}

SIAD is a disorder of sodium and water balance characterized by hypotonic hyponatremia and impaired urinary dilution in the absence of renal disease or any identifiable non-osmotic stimulus known to release ADH. It is a diagnosis of exclusion.

\section{Pathophysiology of SIAD}

The pathophysiological basis of SIAD is an absolute increase in body water. This increase depends on an excessive water intake that overwhelms the restricted renal 
ability of diluting urine and mounting compensatory diuresis due to ADH dysregulation.

Excessive water intake, mainly due to iatrogenic water administration or inappropriate thirst, whose threshold results in downward reset in patients with SIAD [18] and $\mathrm{ADH}$ dysregulation, are both necessary for the full development of this syndrome, accounting for the body water expansion that in turn, through plasmatic sodium dilution, causes hypotonic hyponatremia. Actually, the process is more complicated since, to compensate for ECF expansion, aldosterone secretion is inhibited while atrial natriuretic peptide (ANP) increases. These compensative responses serve to maintain euvolemia, but at the same time, determining natriuresis and body exchangeable sodium loss, further worsen hyponatremia [19].

However, in some cases this initial natriuresis is followed by an increase in urine volume and free water loss [20]. This phenomenon, known as 'escape from antidiuresis', has been attributed to the development of partial renal resistance to $\mathrm{ADH}$, due to a paradoxical decrease in AQP2 protein and V2 receptor in the course of chronic overstimulation [21,22]. The escape from antidiuresis is a protective homeostatic mechanism which allows plasma sodium to stabilize and occasionally to rise. The balance among ECF expansion, natriuresis and water excretion could account for the state of clinical euvolemia present in the patients affected by SIAD. Finally, it is noteworthy that in such a complex pathophysiological condition, independent factors like reduction in sodium intake, diuretic therapy and gastrointestinal loss might contribute to hyponatremia.

\section{Causes of SIAD}

The main causes of SIAD, summarized in table 1 , can be divided into endogenous (A), exogenous (B) and idiopathic $(\mathrm{C})$.

A. Endogenous causes can be further divided into: (1) eutopic non-osmotic ADH release by the posterior pituitary gland; (2) ectopic production of $\mathrm{ADH}$; (3) factors enhancing renal effects of $\mathrm{ADH}$, and (4) $\mathrm{ADH}$-like effect caused by different activating gene mutations along ADH-dependent pathways [23].

(1) ADH eutopic non-osmotic production may be triggered by cerebral insults, like infections, malignancies, cerebrovascular diseases and multiple sclerosis. Many drugs have been associated with SIAD by direct stimulation of ADH release. Among these, the selective serotonin reuptake inhibitors (SSRIs) are the most common and between 0.5 and $32 \%$ of patients treated with SSRIs experience SIAD [24]. Pulmonary diseases are another common cause of SIAD, which can be diagnosed in the course of bacterial pneumonia, tuberculosis and asthma [25].

(2) $\mathrm{ADH}$ ectopic production derives from transformed cells, mainly in the course of lung small cell carcino$\mathrm{ma}$, but also in other malignancies, such as pancreatic carcinoma and lymphomas.

(3) Increased AQP2 expression, leading to a state of relative enhanced renal sensitivity to $\mathrm{ADH}$, has been recognized as the cause of SIAD during treatments with carbamazepine and cyclophosphamide [26, 27].

(4) Recently, attention has been focused on the so-called 'nephrogenic SIAD' (NSIAD), a rare clinical condition due to gene mutations in $\mathrm{V} 2$ receptor and consequent constitutive activation of ADH receptor [28].

$B$. Exogenous forms of SIAD could be due to excessive administration of ADH or its analogs, such as desmopressin acetate (DDAVP).

C. Idiopathic forms of SIAD are a diagnosis of exclusion of $\mathrm{A}$ and $\mathrm{B}$.

\section{Classification of SIAD}

Four different patterns of osmoregulatory defects (from A to D) have been described in the course of SIAD, according to plasmatic $\mathrm{ADH}$ variations following the infusion of hypertonic saline solution (table 2) [29]. Types $\mathrm{A}, \mathrm{B}$, and $\mathrm{C}$ are attributed to a demonstrable defect in the osmoregulation of $\mathrm{ADH}$. The difference between them remains in the fluctuations of plasmatic ADH levels (table 2). On the contrary, type $\mathrm{D}$ is the expression of the above cited NSIAD, being characterized by gain-of-function mutations in V2 receptor and suppression of plasmatic $\mathrm{ADH}$ to undetectable levels, which begins to rise, with an increase in plasma osmolarity, as a consequence of preserved central osmoregulation [30]. The evidence that this syndrome does not constantly depend on central osmoregulation defect led to the new definition of SIAD, considered more accurate than the older SIADH.

\section{Diagnostic Criteria and Differential Diagnosis}

SIAD is diagnosed by exclusion and it must be distinguished from several other conditions of hyponatremia. In table 3 we report the criteria that have been suggested to define SIAD. Despite the number of proposed algo- 
Table 1. Causes of SIAD [adapted from 83]

\begin{tabular}{|c|c|c|}
\hline Classes & & Diseases \\
\hline \multirow[t]{4}{*}{ Endogenous } & 1 & $\begin{array}{l}\text { Increased hypothalamic production of ADH (eutopic) } \\
\text { - } \quad \text { Neuropsychiatric } \\
\text { - } \quad \text { Infections: meningitis, encephalitis, abscess } \\
\text { - } \quad \text { Vascular: thrombosis, subarachnoid or subdural hemorrhage } \\
\text { - } \quad \text { Cerebral malignancies } \\
\text { - } \quad \text { Other cerebral disease: HIV, Guillain-Barré syndrome, acute intermittent porphyria, autonomic neu- } \\
\text { ropathy, post-pituitary surgery, multiple sclerosis, psychosis } \\
\text { - Drugs: } \\
\quad \text { Chemotherapeutics - cyclophosphamide, vincristine, vinblastine } \\
\text { Antipsychotic - thiothixene, thioridazine, haloperidol } \\
\text { Antidepressants - monoamine oxidase inhibitors } \\
\text { Tricyclic antidepressants } \\
\quad \text { Selective serotonin reuptake inhibitors } \\
\text { Miscellaneous - bromocriptine, 3,4-MDMA ('ecstasy') } \\
\text { - Pulmonary diseases: pneumonia, tuberculosis, cystic fibrosis, acute respiratory failure, positive pressure } \\
\text { ventilation, asthma, atelectasis } \\
\text { - Severe nausea, pain (post-surgery) }\end{array}$ \\
\hline & 2 & $\begin{array}{l}\text { Ectopic production of ADH } \\
\text { - Malignancies: } \\
\text { Oat cell of lung, bronchogenic carcinoma, mesotheliom } \\
\text { Carcinoma of duodenum, pancreas, or thymus } \\
\text { Olfactory neuroblastoma } \\
\text { Lymphoma, leukemia } \\
\text { Ewing's sarcoma }\end{array}$ \\
\hline & 3 & Potentiation of ADH effect: chlorpropamide, tolbutamide, carbamazepine, cyclophosphamide \\
\hline & 4 & Nephrogenic syndrome of inappropriate antidiuresis (NSIAD) \\
\hline Exogenous & & Administration of $\mathrm{ADH}$ or its analogues (desmopressin, vasopressin, oxytocin) \\
\hline Idiopathic & & - \\
\hline
\end{tabular}

Table 2. Types of SIAD according to different underlying osmoregulatory dysfunctions

\begin{tabular}{llllll}
\hline & $\begin{array}{l}\text { Preva- } \\
\text { lence }\end{array}$ & Basal urine osmolality & $\begin{array}{l}\text { Basal ADH levels } \\
\text { (in hyponatremic state) }\end{array}$ & $\begin{array}{l}\text { ADH levels after hypertonic } \\
\text { solutions infusion }\end{array}$ & Hypothesized mechanisms \\
\hline A & $30 \%$ & high and constant & high, random fluctuations & no effects & $\begin{array}{l}\text { excessive ADH secretion } \\
\text { (mainly by tumors) }\end{array}$ \\
\hline B & $30 \%$ & $\begin{array}{l}\text { high and constant } \\
\text { (lower than type A) }\end{array}$ & high (lower than type A) & $\begin{array}{l}\text { further pathologic ADH increase } \\
\text { after hyponatremia correction }\end{array}$ & $\begin{array}{l}\text { neurohypophysis injury } \\
\text { osmoregulatory disorders }\end{array}$ \\
\hline C & $30 \%$ & low & low & $\begin{array}{l}\text { inappropriate ADH increase } \\
\text { before hyponatremia correction }\end{array}$ & $\begin{array}{l}\text { osmoregulatory system } \\
\text { downward reset }\end{array}$ \\
\hline D & $10 \%$ & high & undetectable & $\begin{array}{l}\text { appropriate ADH increase after } \\
\text { hyponatremia correction }\end{array}$ & $\begin{array}{l}\text { mutation in V2 receptors } \\
\text { or AQP2 genes }\end{array}$ \\
\hline
\end{tabular}


Table 3. Diagnosis of SIAD [adapted from 1, 2, 84]

\section{Essential features}

Decreased effective plasmatic osmolality $(<275 \mathrm{mosm} / \mathrm{kg})$

Increased urinary osmolality $(>100 \mathrm{mosm} / \mathrm{kg}$ during hypotonicity)

Increased urinary sodium ( $>40 \mathrm{mmol} / \mathrm{l}$ with normal dietary salt intake)

Clinical euvolemia

Normal thyroid and adrenal function

No recent use of diuretic agents

Supplemental features

Reduced serum uric acid $(<4 \mathrm{mg} / \mathrm{dl})$

Reduced BUN $(<10 \mathrm{mg} / \mathrm{dl})$

Fractional sodium excretion $>1 \%$; fractional urea excretion $>55 \%$

Failure to correct hyponatremia after 2 -liter infusion of $0.9 \%$ saline

Correction of hyponatremia through fluid restriction

Abnormal result on test of water load or inadequate urinary dilution

Elevated plasma ADH levels, despite the presence of hypotonicity and clinical euvolemia

$\mathrm{ADH}$ levels are not a reliable marker since they are fluctuant in the different types of SIAD (see table 2).

rithms, the evaluation of hyponatremia remains complex [31] and it requires a complete medical history, physical examination, plasmatic and urinary osmolarity and sodium assessment (table 4); ADH levels, instead, are not useful since they are fluctuant in the different types of SIAD. The patient should be questioned about the use of diuretics and other drugs, including sulfonylureas, tricyclic antidepressants, cyclophosphamide, SSRIs, etc. Information about patient's daily water intake, renal, hepatic or cardiac disease, diarrhea and vomiting, and history of trauma, radiotherapy or surgery should also be obtained.

The laboratory evaluation of hyponatremia should start measuring serum osmolality to confirm true hyponatremia, excluding two different situations: pseudo-hyponatremia, a laboratory artifact due to very high lipid or protein levels, and hypertonic translocational hyponatremia, due to the presence of osmotically active solutes, such as glucose or mannitol, which drive free water outside the cells. Urine osmolality and sodium concentration must be regarded to verify the presence of high osmolality (>100 mosm $/ \mathrm{kg}$, except for type C SIAD; table 2) and high sodium concentration (usually $>40 \mathrm{mmol} / \mathrm{l}$ ).

Then, clinical evaluation of ECF may contribute to distinguish among hypovolemic, euvolemic and hyper- volemic causes of hyponatremia [32]. Edema and high jugular venous pressure remains for ECF expansion, as in chronic heart failure, nephrotic syndrome and cirrhosis. On the contrary, hypotension, tachycardia, dry mucosae, reduced skin turgor and low central venous pressures remain for hypovolemia, as in the case of renal and extrarenal sodium loss. However, it should be warned that assessment of the volemic state by physical examination, hemodynamic parameters and laboratory analysis is often not very reliable in the clinical practice, so it is only supportive in the differentiation of hyponatremia [33].

Cerebral and renal salt wasting syndromes (SWS) require special attention for diagnosis. They are characterized by hyponatremia and ECF depletion, caused by an abnormal renal excretion of sodium mainly in patients with insults to the central nervous system [34]. Both SWS and SIAD present hyponatremia, concentrated urine and natriuresis, but SWS is defined by a hard-to-recognize ECF depletion. In case of diagnostic uncertainty, correction of hyponatremia with the infusion of 2 liters of $0.9 \%$ saline over a period of $24-48 \mathrm{~h}$ (a safe procedure even in SIAD when baseline urinary osmolality is $<500 \mathrm{mosm} /$ $\mathrm{kg}$ ) suggests a diagnosis of hypovolemic hyponatremia.

Euvolemic hyponatremia, that is the clinical feature of SIAD, occurs also in the course of endocrine diseases, such as hypothyroidism and ACTH deficiency, primary polydipsia and excessive iatrogenic fluid replacement, mainly after the surgical procedure. Differential diagnosis may be guided by laboratory findings, such as hormone level and urinary osmolality, that results in being reduced $(<100 \mathrm{mosm} / \mathrm{kg})$ over the course of polydipsia [35]. ACTH deficiency should be ruled out before making a diagnosis of SIAD. Although it could be difficult because of the same biochemical picture found in SIAD [36], a correct diagnosis of ACTH deficiency allows a glucocorticoid replacement therapy that has been shown to normalize excretion of free water and plasma sodium concentrations [37].

Finally, other minor diagnostic clues may help clinicians to better define SIAD. Blood urea nitrogen and uric acid levels are typically low in the course of SIAD, as opposed to diuretic-induced hyponatremia [38].

\section{Clinical Picture and Management}

The clinical picture depends on hyponatremia severity, progression rate and intra- to extracellular osmotic gradient entity. Neurological manifestations dominate the clinical presentation [39]. Due to hyposmolality, free 
Table 4. Differential diagnosis of hyponatremia

\begin{tabular}{|c|c|c|c|c|c|c|c|}
\hline \multirow{2}{*}{$\begin{array}{l}\text { Volemic state: } \\
\text { Underlying diseases: }\end{array}$} & \multirow{2}{*}{$\begin{array}{l}\text { Hypervolemia } \\
\text { CHF, } \\
\text { cirrhosis, } \\
\text { nephrotic } \\
\text { syndrome }\end{array}$} & \multicolumn{3}{|l|}{ Hypovolemia } & \multicolumn{3}{|l|}{ Euvolemia } \\
\hline & & $\begin{array}{l}\text { bleeding, } \\
\text { diuretic, } \\
\text { diarrhea }\end{array}$ & $\begin{array}{l}\text { salt wasting } \\
\text { syndromes }\end{array}$ & $\begin{array}{l}\text { adrenal } \\
\text { insufficiency }\end{array}$ & $\begin{array}{l}\text { primary polydipsia, } \\
\text { hypothyroidism }\end{array}$ & $\begin{array}{l}\text { drug } \\
\text { nausea, } \\
\text { hypocortisolemia }\end{array}$ & SIAD $^{1}$ \\
\hline Edema & + & - & - & - & - & - & - \\
\hline Blood pressure & low & low & low & low & normal/low & normal/low & normal \\
\hline Urine sodium excretion & low & low $^{2}$ & high & high & low & high & high $^{3}$ \\
\hline Plasma renin activity & high & high & high & high & low & low & low \\
\hline Additional criteria & - & $\begin{array}{l}\text { metabolic } \\
\text { acidosis } \\
\text { (in diarrhea) }\end{array}$ & $\begin{array}{l}\text { response to } \\
\text { saline infusion }\end{array}$ & $\begin{array}{l}\text { hyperkalemia, } \\
\text { hormone } \\
\text { dosing }\end{array}$ & hormone dosing & hormone dosing & $\begin{array}{l}\text { low BUN } \\
\text { and uric acid }\end{array}$ \\
\hline
\end{tabular}

$\mathrm{CHF}=$ Chronic heart failure; $\mathrm{SIAD}=$ syndrome of inappropriate antidiuresis; $\mathrm{BUN}=$ blood urea nitrogen .

${ }^{1}$ Also investigate secondary causes for ADH increase (i.e. chronic pain, cerebral or pulmonary diseases and malignancies). ${ }^{2}$ Except in diuretic abuse. ${ }^{3}$ Except for type C SIAD (see table 2).

water enters brain cells, leading to acute cerebral edema; at serum sodium concentrations $<125 \mathrm{mEq} / \mathrm{l}$, apathy, weakness, headaches, nausea and vomiting develop; at concentrations $<115 \mathrm{mEq} / \mathrm{l}$, altered consciousness, seizures, coma, respiratory arrest and death can occur [40]. Medical care and management mainly depend on the clinical picture and timing of the development of hyponatremia, i.e. acute vs. chronic forms. The priority must be given to the correction of life-threatening conditions, which usually accompany acute symptomatic presentation of hyponatremia. Fluid restriction to less than the rate of urinary water excretion has been suggested as the initial treatment in stable asymptomatic patients [41]. Because of the difficult compliance to this prescription and the delay of its therapeutic action, saline infusion has arisen as the cornerstone of the treatment. Isotonic saline solution $(0.9 \%)$ should be reserved for mild symptomatic patients and those cases of difficult differentiation between hypovolemic and euvolemic status.

Moreover, the infusion of isotonic solution to a patient with SIAD who presents a fixed elevated urine osmolality can result in further dilution and decrease of serum sodium levels. This phenomenon, also known as desalination, depends on the retention of electrolyte-free water that occurs when the osmolality of an infused solution is lower than the patient's urinary osmolality [42].

For these reasons, acute and more severe conditions require administration of hypertonic saline solution (3 or $5 \%$ ); the correction speed must be adequate and slower than $12 \mathrm{mmol} / \mathrm{l} /$ day because of the risk of osmotic demyelination syndrome $[43,44]$. Osmotic demyelination entails both central pontine and extrapontine irreversible myelinolysis. Generally, after an initial improvement of neurologic symptoms, it presents with lethargy, followed by dysarthria, spastic quadriparesis and pseudobulbar palsy. The need for a safe correction of hyponatremia has been conducted for the development of mathematical formulas, such as the one of Adrogué and Madias [45] (for free access to online calculator, see http://www.medcalc.com/sodium. $\mathrm{html})$. However, in clinical practice the simplest strategy is to infuse $3 \%$ hypertonic saline solution at a rate of 1-2 $\mathrm{ml} /$ $\mathrm{kg}$ body weight per hour, increasing serum sodium levels by $0.5 \mathrm{mmol} / \mathrm{l} / \mathrm{h}$, and to closely monitor plasma sodium levels every $2 \mathrm{~h}$ [46]. Infusion can be increased up to $4 \mathrm{ml} /$ $\mathrm{kg} / \mathrm{h}$ for a limited period of time in the presence of coma or seizures. The sodium concentration should not rise at a rate exceeding $2 \mathrm{mmol} / \mathrm{l} / \mathrm{h}$ and $12 \mathrm{mmol} / \mathrm{l} / 24 \mathrm{~h}$, avoiding an increase of $>18 \mathrm{mmol} / \mathrm{l}$ during the first $48 \mathrm{~h}$ and paying attention to not exceed $8 \mathrm{mmol} / \mathrm{l}$ during the first $24 \mathrm{~h}$ of treatment in diabetic or alcohol-addicted patients who are at greater risk of myelinolysis.

The infusion of DDAVP has been described as an effective and safe strategy to prevent or eventually reverse an inadvertent overcorrection of hyponatremia, even if the increased sodium levels had already exceeded the intended limit [47].

Furosemide has been reported as an additive treatment for SIAD, effective in the initial phase because of its 
ability of increasing free water excretion through the induction of hypertonic diuresis and the loss of medullary concentration gradient [48]. However, it seems that this strategy could be effective only during the acute phase of correction, since few results of long-term treatment have been reported [49]. Therapeutic options for SIAD also include treatments which actually are not widely used in routine clinical practice. Demeclocycline hydrochloride (300-600 mg twice daily) is a tetracycline derivative that, through a not well-defined mechanism, induces nephrogenic diabetes insipidus, reducing urine osmolality and increasing serum sodium levels [50]; unfortunately, its use has been banned due to frequent side effects, such as nausea, skin photosensitivity and nephrotoxicity [51]. Lithium carbonate also causes nephrogenic diabetes insipidus and reduces renal ability of concentrating urine through the downregulation of AQP2 [52]; because of its association to renal toxicity and interstitial nephritis, it has been abandoned as a drug for SIAD [53]. Urea oral intake (15-60 g/day) is effective in increasing free water clearance [41] and it is useful in young children affected by NSIAD [54], but its long-term administration is highly limited by poor palatability and bitter taste.

Recently, new therapeutic options have been evaluated, in particular vasopressin receptor antagonists, the socalled vaptans [55].

\section{Vasopressin Receptor Antagonist Therapy: Mechanisms, Indications and Clinical Experiences}

Non-peptide vasopressin receptor antagonists are a new class of drugs, currently under study as a treatment option for SIAD. These molecules, known as vaptans or aquaretics, block ADH V2 receptors and decrease AQP2 at renal collecting ducts, which result in being insensitive to $\mathrm{ADH}$ and become less permeable to water, thus leading to an increased urinary excretion of free water [56].

Several members of this drug family, such as conivap$\tan [57-59]$, satavaptan [60, 61], tolvaptan [62, 63] and lixivaptan [64], have been reported to increase serum sodium in patients with hyponatremia. A recent meta-analysis including 15 randomized controlled trials showed early and late efficacy and safety of these drugs [65]. Until now only two vaptans have been released for general use: conivaptan, available as an intravenous preparation, and tolvaptan, as an oral tablet.

Conivaptan hydrochloride (Vaprisol) is a non-peptide benzazepine derivate that acts as a non-selective vasopressin V1a/V2 receptor antagonist. Conivaptan was ap- proved in 2005 by the FDA (USA) for intravenous treatment of moderate to severe euvolemic hyponatremia and then, in 2007, for hypervolemic hyponatremia in hospitalized patients [66]. The loading dose is $20 \mathrm{mg}$ i.v. to infuse over $30 \mathrm{~min}$ and the maintenance dose is $20 / 40 \mathrm{mg}$ i.v. for continuous infusion over $24 \mathrm{~h}$ up to 4 days. The drug is metabolized only by liver cytochrome CYP3A4 and the metabolites are excreted with feces [67]; the coadministration with other drugs metabolized by CYP3A4 (i.e. ketoconazole, amlodipine, simvastatin, clarithromycin, ritonavir, indinavir) could result in an increased risk of toxicity. Common side effects are infusion site reactions, fever, hypokalemia and gastrointestinal disturbances; moreover, conivaptan is associated with the risk of hypotension, since it may induce vasodilatation blocking the V1a receptor.

Different studies have shown conivaptan efficacy in increasing the serum sodium concentration both in the case of euvolemic and hypervolemic hyponatremia [58, 59, 68-71]. Actually, these early studies considered cases of hyponatremia of different etiologies, but a randomized controlled trial specifically targeted on SIAD treatment has not been reported so far. Recently, the results of a single-center experience in the treatment of SIAD with conivaptan have been published [72]. It is a retrospective study which tested conivaptan efficacy on 18 patients, presenting moderate to severe hyponatremia due to SIAD and unresponsive to free water restriction, saline infusion or demeclocycline. All the patients had at least a 3 -mmol/l serum sodium level increase and 12 patients (66.7\%) reached the primary end-point (an increase of at least of $4 \mathrm{mmol} / \mathrm{l}$ ), associated with urine osmolality decrease $24 \mathrm{~h}$ after the initiation of conivaptan therapy; this improvement was maintained even at 48 and $72 \mathrm{~h}$ after administration of conivaptan. Three patients (16.7\%) required drug discontinuation because of a too rapid correction of hyponatremia, but none of them presented osmotic demyelination. Sodium correction rates were inversely correlated with baseline serum sodium levels and BUN, and directly associated with creatinine clearance.

Moreover, conivaptan has also been tested in the setting of congestive heart failure (CHF). In this group of patients the use of the drug increased total urine output but had modest effects on filling pressures and cardiac index [73]. Unlike conivaptan, tolvaptan (Samsca) is a selective vasopressin V2-receptor antagonist, approved by the FDA (USA) for treatment of hypervolemic and euvolemic hyponatremia, including patients with heart failure, cirrhosis and SIAD, while by EMEA (EU) only for SIAD $[74,75]$. 
Fig. 1. Algorithm for the treatment of SI$\mathrm{AD}$-related hyponatremia.

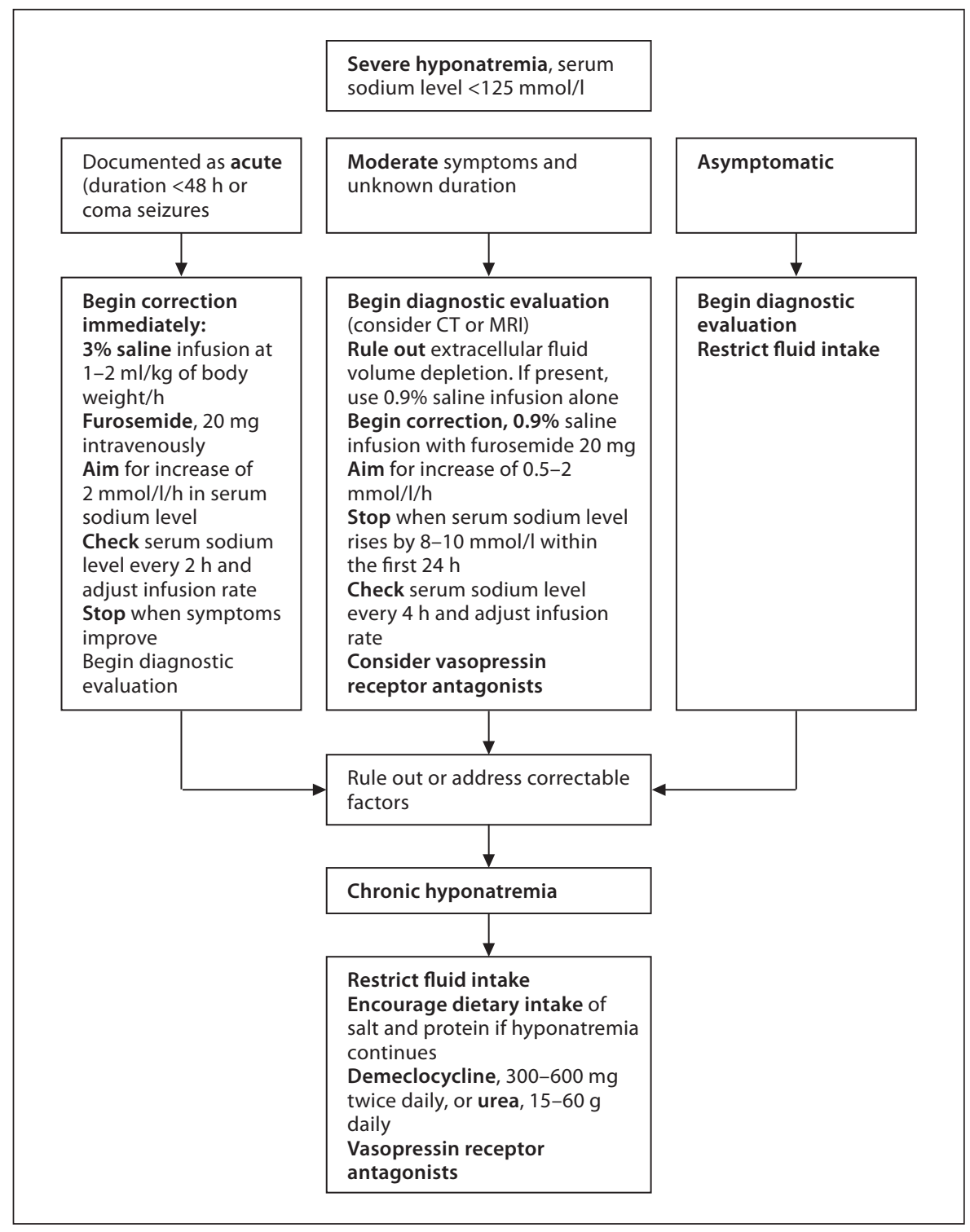

Pharmacodynamic and pharmacokinetic profiles are quite similar to conivaptan. The initial dosage is $15 \mathrm{mg}$ once daily, which is increased to $30-60 \mathrm{mg}$ depending on clinical response. Like conivaptan, tolvaptan is metabolized primarily by the CYP3A4, so there are warnings about drug interactions. The main adverse reactions are weakness, constipation, dry mouth, polyuria, thirst and hyperglycemia. Notably, this drug is not associated with hypotension, because of the selective antagonism on vasopressin V2 receptor. It is contraindicated when there is a need for an acute increase of serum sodium levels, in hypovolemic hyponatremia and in patients unable to sense or express thirst. Concomitant fluid restriction and hypertonic saline infusion should be avoided and patients should have free access to water to avert the risk of the osmotic demyelination syndrome.

The efficacy of tolvaptan has been proven in large randomized clinical trials [76]. The 'Study of Ascending Levels of Tolvaptan in Hyponatremia 1 and 2' (SALT-1 and SALT-2) trials were two identical randomized, doubleblind, placebo-controlled, multicenter studies which examined the effects of tolvaptan on hypervolemic and euvolemic hyponatremia $(<135 \mathrm{mmol} / \mathrm{l})$, associated with chronic heart failure, cirrhosis, SIADH or other causes (about 35, 25 and $40 \%$ of the studied patients, respectively) [64]. Patients were randomized to receive tolvaptan or 
placebo as an adjunct to standard medical treatment. Tolvaptan was administrated once daily for up to 30 days at the initial dose of $15 \mathrm{mg}$ and was increased up to a maximum of $60 \mathrm{mg} /$ day during the initial 4 days of therapy, according to the response. The two primary endpoints were the change in the average daily area under the curve for serum sodium concentration from baseline to day 4 and day 30. A total of 213 patients randomized to receive tolvaptan (95 in SALT-1 and 118 in SALT-2) and 203 placebo recipients (89 in SALT-1 and 114 in SALT-2) were analyzed. Tolvaptan treatment resulted in significantly ( $<<0.001)$ higher mean serum sodium levels compared to placebo just within $8 \mathrm{~h}$ after administration of the first dose. This statistical difference was maintained at all follow-up visits at day 4 and day 30. Among tolvaptan recipients, serum sodium levels increased from 128.5 $\mathrm{mmol} / \mathrm{l}$ at baseline to $133.9 \mathrm{mmol} / \mathrm{l}$ on day 4 and 135.7 $\mathrm{mmol} / 1$ on day 30 in SALT-1 ( $\mathrm{p}<0.001$ vs. placebo group). In the experimental group there was also a significant increase of urine output, a tendency to decrease the requirement of fluid restriction, and a significant improvement of scores on the Mental Component of the Medical Outcomes Study 12-item Short-Form (SF-12) from baseline to day 30. The most common adverse effects were thirst and dry mouth, while 4 treated patients experienced overcorrection of hyponatremia.

The more recent 'Safety and sodium Assessment of Long-term Tolvaptan With hyponatremia: A year-long, open-label Trial to gain Experience under Real-world conditions' (SALTWATER) trial was thought as an openlabel extension study of the SALTs program, aiming to evaluate the long-term effects of tolvaptan in terms of safety and efficacy [77]. 111 patients with different causes of hyponatremia (CHF 29.7\%, cirrhosis $18.0 \%$, and SIADH/other 52.3\%), already enrolled in SALT-1 and 2 protocols, were treated with tolvaptan and followed up for a mean of 701 days. Tolvaptan treatment resulted in serum sodium level increase in all the patients, who reached normal values within 4 weeks in more than $40 \%$ of the cases. The treatment was associated with a number of adverse effects: mild, such as pollakiuria, thirst, and fatigue, and severe, such as ventricular tachycardia, anorexia, and serum creatinine increase. Although this study suffered from the lack of a control group, its findings suggest that tolvaptan is effective but close monitoring is required.

Besides SIAD and hyponatremia, tolvaptan has also been tested in the setting of acute heart failure. In small studies, the administration of tolvaptan at a dose of 30 , 60 or $90 \mathrm{mg} /$ day was associated with significantly greater reductions in median body weight compared to placebo $[78,79]$. The 'Efficacy of Vasopressin Antagonism in Heart Failure Outcome Study With Tolvaptan' (EVEREST) A and B trials were two identical, randomized, double-blind, placebo-controlled studies in which 4,133 patients, hospitalized with acute heart failure, were randomized to receive tolvaptan $30 \mathrm{mg}$ or placebo [80, 81]. Tolvaptan administration in a total of 2,072 patients was associated with an improvement of both the primary end-point, a composite of changes in global clinical status score and body weight, and the secondary end-points, dyspnea and peripheral edema. Unfortunately, the longterm evaluations showed no statistically significant difference in mortality compared to placebo groups.

Adverse events occurred both in the tolvaptan and placebo group but only thirst, polyuria, dry mouth and hypernatremia, all consistent with the mechanism of action of the drug, occurred significantly more frequently with tolvaptan. Overall, also considering the data on the use of conivaptan in CHF, it seems that in patients with heart failure the use of vaptans is only associated with improved clinical symptoms of congestion, but it does not alter the progression of the disease or affect patient mortality [82]. However, it should be underlined that also in the EVEREST trials, tolvaptan confirmed its effect on serum osmolality. In fact in the subgroup of 323 patients with hyponatremia (serum sodium $<134 \mathrm{mmol} / \mathrm{l}$ ) at baseline, in the tolvaptan arm there was a significantly greater increase in mean serum sodium levels from baseline to day 7, maintained until week 40 .

Finally, considering all the treatment options discussed above and on the basis of the reported evidence, we suggest an algorithm to guide therapeutic decisionmaking in the cases of SIAD-related hyponatremia (fig. 1). We think that this approach, considering also the new data on vaptans, could help in the difficult management of patients affected by SIAD.

\section{Conclusions}

SIAD is a frequent cause of hyponatremia in the clinical setting, with a wide spectrum of clinical manifestations, from asymptomatic forms to life-threatening conditions. Therefore, the correct diagnosis is mandatory and an accurate assessment of comorbidities, patient volume status and laboratory findings is required. Traditional treatment options for SIAD include fluid restriction, saline infusion, furosemide, demeclocycline and urea, but all have their limitations and no guidelines are 
available. In addition, the risk of hyponatremia overcorrection should be avoided, closely monitoring the response to treatment and, maybe, using DDAVP infusion as a preventive strategy.

In this hard context, the introduction of the vasopressin receptor antagonists in clinical practice seems to offer clinicians an interesting therapeutic tool which is effective and safe in the treatment of mild to moderate hyponatremia. However, we need to develop an integrated and standardized approach for the treatment of acute and chronic SIAD-related hyponatremia. Many efforts have been made but new data from prospective randomized trials are needed, also to help physicians translate the experimental evidence into real clinical practice.

\section{Disclosure Statement}

The authors have no conflicts of interest to disclose.

\section{References}

1 Schwartz WB, Bennett W, Curelop S, Bartter FC: A syndrome of renal sodium loss and hyponatremia probably resulting from inappropriate secretion of antidiuretic hormone. Am J Med 1957;23:529-542.

2 Ellison DH, Berl T: The syndrome of inappropriate antidiuresis. N Engl J Med 2007; 356:2064-2072.

3 Schally AV: Hormones of the neurohypophysis; in Lock W, Schally AV (eds): The Hypothalamus and Pituitary in Health and Disease. Springfield, Thomas, 1972, pp 154-171.

-4 Tsujimoto M, Goto Y, Maruyama M, Hattori A: Biochemical and enzymatic properties of the M1 family of aminopeptidases involved in the regulation of blood pressure. Heart Fail Rev 2008;13:285-291.

5 Durr JA, Hoggard JG, Hunt JM, Schrier RW: Diabetes insipidus in pregnancy associated with abnormally high circulating vasopressinase activity. N Engl J Med 1987;316:10701074.

6 Ball SG: Vasopressin and disorders of water balance: the physiology and pathophysiology of vasopressin. Ann Clin Biochem 2007; 44:417-431.

7 Altura BM, Altura BT: Actions of vasopressin, oxytocin, and synthetic analogs on vascular smooth muscle. Fed Proc 1984;43:8086.

8 Thibonnier M, Conarty DM, Preston JA, et al: Molecular pharmacology of human vasopressin receptors. Adv Exp Med Biol 1998; 449:251-276.

-9 Du Pasquier D, Loup F, Dubois-Dauphin M, et al: Binding sites for vasopressin in the human pituitary are associated with corticotrophs and may differ from other known vasopressin receptors. J Neuroendocrinol 1991; 3:237-247.

10 Nielsen S, Frokler J, Marples D, Kwon T, et al: Aquaporins in the kidney from molecules to medicine. Physiol Rev 2002;82:205-244.

11 Bankir L: Antidiuretic action of vasopressin: quantitative aspects and interaction between V1A and V2 receptor-mediated effects. Cardiovasc Res 2001;51:372-390.
12 McKinley MJ, Mathai M, McAllen RM, et al: Vasopressin secretion: osmotic and hormonal regulation by the lamina terminalis. J Neuroendocrinol 2004;16:340-347.

13 Baylis PH, Thompson CJ: Osmoregulation of vasopressin secretion and thirst in health and disease. Clin Endocrinol 1988;29:549576.

14 Goetz KL, Zhu JL, Leadley RJ, et al: Hemodynamic and hormonal influences on the secretion of vasopressin; in Jard S, Jamison R (eds): Vasopressin. Montrouge, Libbey, 1991, pp 279-286.

15 Brooks VL, Keil LC, Reid IA: Role of the renin-angiotensin system in the control of vasopressin secretion in conscious dogs. Circ Res 1986;58:829-838.

16 Goldsmith SR, Dodge D, Cowley AW: Nonosmotic influences on osmotic stimulation of vasopressin in humans. Am J Physiol 1987; 252:H85-H88.

17 Kendler KS, Weitzman RE, Fisher DA: The effect of pain on plasma arginine vasopressin concentrations in man. Clin Endocrinol (Oxf) 1978;8:89-94.

18 Smith D, Moore K, Tormey W, et al: Downward resetting of the osmotic threshold for thirst in patients with SIADH. Am J Physiol Endocrinol Metab 2004;287:E1019-E1023.

19 Manoogian C, Pandian M, Ehrlich L, et al: Plasma atrial natriuretic hormone levels in patients with the syndrome of inappropriate antidiuretic hormone secretion. J Clin Endocrinol Metab 1988;67:571-575.

20 Levinsky NG, Davidson DG, Berliner RW: Changes in urine concentration during prolonged administration of vasopressin and water. Am J Physiol 1959;196:451-456.

21 Ecelbarger CA, Nielsen S, Olson BR: Role of renal aquaporins in escape from vasopressin induced antidiuresis in rat. J Clin Invest 1997;99:1852-1863.

22 Tian Y, Sandberg K, Murase T, et al: Vasopressin V2 receptor binding is down-regulated during renal escape from vasopressininduced antidiuresis. Endocrinology 2000; 141:307-314.
23 Hoorn EJ, Zietse R: Hyponatremia revisited: translating physiology to practice. Nephron Physiol 2008;108:46-59.

24 Jacob S, Spinler SA: Hyponatremia associated with selective serotonin-reuptake inhibitors in older adults. Ann Pharmacother 2006;40:1618-1622.

-25 Coyle S, Penney MD, Masters PW, Walker BE: Early diagnosis of ectopic arginine vasopressin secretion. Clin Chem 1993;39:152154.

26 De Bragança AC, Moyses ZP, Magaldi AJ: Carbamazepine can induce kidney water absorption by increasing aquaporin-2 expression. Nephrol Dial Transplant 2010;25: 3840-3845.

27 Park SJ, Kim JH, Shin JI: Insight on mechanism of hyponatraemia induced by lowdose intravenous pulse cyclophosphamide. Nephrol Dial Transplant 2010;25:34533454.

28 Levtchenko EN, Monnens LA: Nephrogenic syndrome of inappropriate antidiuresis. Nephrol Dial Transplant 2010;25:28392843.

29 Robertson GL: Regulation of arginine vasopressin in the syndrome of inappropriate antidiuresis. Am J Med 2006;119:S36-S42.

30 Feldman BJ, Rosenthal SM, Vargas GA: Nephrogenic syndrome of inappropriate antidiuresis. N Engl J Med 2005;352:18841890.

- 31 Fenske W, Maier SK, Blechschmidt A, et al: Utility and limitations of the traditional diagnostic approach to hyponatremia: a diagnostic study. Am J Med 2010;123:652-657.

32 Hannon MJ, Thompson CJ: The syndrome of inappropriate antidiuretic hormone: prevalence, causes and consequences. Eur J Endocrinol 2010;162(suppl 1):S5-S12.

33 Chung HM, Kluge R, Schrier RW, Anderson RJ: Clinical assessment of extracellular fluid volume in hyponatremia. Am J Med 1987;83: 905-908.

34 Cerdà-Esteve M, Cuadrado-Godia E, Chillaron JJ, et al: Cerebral salt wasting syndrome. Eur J Intern Med 2008;19:249-254. 
35 Milionis HJ, Liamis GL, Elisaf MS: The hyponatremic patient: a systematic approach to laboratory diagnosis. CMAJ 2002;166:10561062.

-36 Green HH, Harrington AR, Valtin H: On the role of antidiuretic hormone in the inhibition of acute water diuresis in adrenal insufficiency and the effects of gluco- and mineralocorticoids in reversing the inhibition. J Clin Invest 1970;49:1724-1736.

37 Olchovsky D, Ezra D, Vered I, et al: Symptomatic hyponatremia as a presenting sign of hypothalamic-pituitary disease: a syndrome of inappropriate secretion of antidiuretic hormone (SIADH)-like glucocorticosteroidresponsive condition. J Endocrinol Invest 2005;28:151-156.

- 38 Decaux G, Musch W: Clinical laboratory evaluation of the syndrome of inappropriate secretion of antidiuretic hormone. Clin J Am Soc Nephrol 2008;3:1175-1184.

-39 Arieff AI, Llach F, Massry SG: Neurological manifestations and morbidity of hyponatremia: correlation with brain water and electrolytes. Medicine 1976;55:121-129.

-40 Ayus JC, Arieff AI: Abnormalities of water metabolism in the elderly. Semin Nephrol 1996;16:277-288

-41 Decaux G, Unger J, Brimioulle S, Mockel J: Hyponatremia in the syndrome of inappropriate secretion of antidiuretic hormone. Rapid correction with urea, sodium chloride, and water restriction therapy. JAMA 1982;247:471-474.

-42 Steele A, Gowrishankar M, Abrahamson S, et al: Postoperative hyponatremia despite near isotonic saline infusion: a phenomenon of desalination. Ann Intern Med 1997;126: $20-25$.

-43 Sterns RH, Riggs JE, Schochet SS Jr: Osmotic demyelination syndrome following correction of hyponatremia. N Engl J Med 1986; 314:1535-1542.

-44 Sterns RH, Cappuccio JD, Silver SM, Cohen EP: Neurologic sequelae after treatment of severe hyponatremia: a multicenter perspective. J Am Soc Nephrol 1994;4:1522-1530.

-45 Adrogué HJ, Madias NE: Hyponatremia. N Engl J Med 2000;342:1581-1589.

-46 Sherlock M, Thompson CJ: The syndrome of inappropriate antidiuretic hormone: current and future management options. Eur J Endocrinol 2010;162(suppl 1):S13-S18.

-47 Perianayagam A, Sterns RH, Silver SM, et al: DDAVP is effective in preventing and reversing inadvertent overcorrection of hyponatremia. Clin J Am Soc Nephrol 2008;3:331-336.

48 Decaux G: Treatment of the syndrome of inappropriate secretion of antidiuretic hormone by long loop diuretics. Nephron 1983; 35:82-88.

49 Ghali JK: Mechanisms, risks and new treatment options for hyponatremia. Cardiology 2008;111:147-157.
50 Perks WH, Walters EH, Tams IP, Prowse K: Demeclocycline in the treatment of the syndrome of inappropriate secretion of antidiuretic hormone. Thorax 1979;34:324-327.

51 Curtis NJ, van Heyningen C, Turner JJ: Irreversible nephrotoxicity from demeclocycline in the treatment of hyponatremia. Age Ageing 2002;31:151-152.

52 Kwon T-H, Laursen UH, Marples D, et al: Altered expression of renal AQPs and $\mathrm{Na}+$ transporters in rats with lithium-induced nephrogenic diabetes insipidus. Am J Physiol Ren Physiol 2000;279:F552-F564.

53 Grunfeld JP, Rossier BC: Lithium nephrotoxicity revisited. Nat Rev Nephrol 2009;5: 270-276.

54 Huang E, Feldman BJ, Schwartz D, et al: Oral urea for the treatment of chronic syndrome of inappropriate antidiuresis in children. J Pediatr 2006; 148:128-131.

55 Decaux G, Soupart A, Vassart G: Non-peptide arginine-vasopressin antagonists: the vaptans. Lancet 2008;371:1624-1632.

56 Costello-Boerrigter LC, Boerrigter G, Burnett JC Jr: Pharmacology of vasopressin antagonists. Heart Fail Rev 2009; 14:75-82.

57 Ghali JK, Koren MJ, Taylor JR, et al: Efficacy and safety of oral conivaptan: A V1A/V2 vasopressin receptor antagonist, assessed in a randomized, placebo-controlled trial in patients with euvolemic or hypervolemic hyponatremia. J Clin Endocrinol Metab 2006;91: 2145-2152.

58 Annane D, Decaux G, Smith N: Efficacy and safety of oral conivaptan, a vasopressin-receptor antagonist, evaluated in a randomized, controlled trial in patients with euvolemic or hypervolemic hyponatremia. Am J Med Sci 2009;337:28-36.

59 Decaux G: Long-term treatment of patients with inappropriate secretion of antidiuretic hormone by the vasopressin receptor antagonist conivaptan, urea, or furosemide. Am J Med 2001;110:582-584.

60 Gines P, Wong F, Watson H, et al: Effects of satavaptan, a selective vasopressin V2 receptor antagonist, on ascites and serum sodium in cirrhosis with hyponatremia: a randomized trial. Hepatology 2008;48:204-213.

61 Soupart A, Gross P, Legros JJ, et al: Successful long-term treatment of hyponatremia in syndrome of inappropriate antidiuretic hormonesecretion with satavaptan (SR121463B), an orally active nonpeptide vasopressin V2 receptor antagonist. Clin J Am Soc Nephrol 2006;1:1154-1160.

62 Gheorghiade M, Gottlieb SS, Udelson JE, et al: Vasopressin V2 receptor blockade with tolvaptan versus fluid restriction in the treatment of hyponatremia. Am J Cardiol 2006;97:1064-1067.

63 Schrier RW, Gross P, Gheorghiade M, et al: Tolvaptan, a selective oral vasopressin V2receptor antagonist, for hyponatremia. $\mathrm{N}$ Engl J Med 2006;355:2099-2112.
64 Wong F, Blei AT, Blendis LM, Thuluvath PJ: A vasopressin receptor antagonist (VPA985) improves serum sodium concentration in patients with hyponatremia: a multicenter, randomized, placebo-controlled trial. Hepatology 2003;37:182-191.

65 Rozen-Zvi B, Yahav D, Gheorghiade M, et al: Vasopressin receptor antagonists for the treatment of hyponatremia: systematic review and meta-analysis. Am J Kidney Dis 2010;56:325-337.

66 Ghali JK, Farah JO, Daifallah S, et al: Conivaptan and its role in the treatment of hyponatremia. Drug Des Devel Ther 2009;3: 253-268.

67 Vaprisol (Conivaptan $\mathrm{HCl}$ Injection) Drug Information: Uses, side effects, drug interactions), December 2008. www.rxlist.com/vaprisol-drug.htm (accessed August 25, 2009).

-68 Goldsmith SR, Elkayam U, Haught WH, et al: Efficacy and safety of the vasopressin V1A/V2-receptor antagonist conivaptan in acute decompensated heart failure: a doseranging pilot study. J Card Fail 2008;14:641647.

69 Wright WL, Asbury WH, Gilmore JL, Samules OB: Conivaptan for hyponatremia in the neurocritical care unit. Neurocrit Care 2009; 11:6-13

70 Verbalis JG, Zeltser D, Smith N, et al: Assessment of the efficacy and safety of intravenous conivaptan in patients with euvolaemic hyponatraemia: subgroup analysis of a randomized, controlled study. Clin Endocrinol 2008;69:159-168.

-71 Zeltser D, Rosansky S, van Rensburg H, et al, Conivaptan Study Group: Assessment of the efficacy and safety of intravenous conivap$\tan$ in euvolemic and hypervolemic hyponatremia. Am J Nephrol 2007;27:447-457.

72 Velez JC, Dopson SJ, Sanders DS, et al: Intravenous conivaptan for the treatment of hyponatremia caused by the syndrome of inappropriate secretion of antidiuretic hormone in hospitalized patients: a single center experience. Nephrol Dial Transplant 2010;25: 1524-1531.

73 Udelson JE, Smith WB, Hendrix GH, et al: Acute hemodynamic effects of conivaptan, a dual V1A and V2 vasopressin receptor antagonist, in patients with advanced heart failure. Circulation 2001;104:2417-2423.

74 Samsca (Tolvaptan): US Prescribing Information. Rockville, Otsuka America Pharmaceutical Inc, 2009.

75 Samsca (Tolvaptan): EU Summary of Product Characteristics. Uxbridge, Otsuka Pharmaceutical Europe Ltd, 2009.

76 Nemerovski C, Hutchinson DJ: Treatment of hypervolemic or euvolemic hyponatremia associated with heart failure, cirrhosis, or the syndrome of inappropriate antidiuretic hormone with tolvaptan: a clinical review. Clin Ther 2010;32:1015-1032. 
77 Berl T, Quittnat-Pelletier F, Verbalis JG, et al, SALTWATER Investigators: Oral tolvaptan is safe and effective in chronic hyponatremia. J Am Soc Nephrol 2010;21:705-712.

78 Gheorghiade M, Niazi I, Ouyang J, et al: Vasopressin V2-receptor blockade with tolvaptan in patients with chronic heart failure: results from a double-blind, randomized trial. Circulation 2003;107:2690-2696.

79 Gheorghiade M, Gattis WA, O’Connor CM, et al: Effects of tolvaptan, a vasopressin antagonist, in patients hospitalized with worsening heart failure: a randomized controlled trial. JAMA 2004;291:1963-1971.
80 Gheorghiade M, Konstam MA, Burnett JC Jr, et al: Short-term clinical effects of tolvaptan, an oral vasopressin antagonist, in patients hospitalized for heart failure: the EVEREST Clinical Status Trials. JAMA 2007;297:13321343.

81 Konstam MA, Gheorghiade M, Burnett JC Jr, et al: Effects of oral tolvaptan in patients hospitalized for worsening heart failure: the EVEREST Outcome Trial. JAMA 2007;297: 1319-1331.
82 Nemerovski C, Hutchinson DJ: Treatment of hypervolemic or euvolemic hyponatremia associated with heart failure, cirrhosis, or the syndrome of inappropriate antidiuretic hormone with tolvaptan: a clinical review. Clin Ther 2010;32:1015-1032.

83 Rose BD, Post TW: Clinical Physiology of Acid-Base and Electrolyte Disorders, ed 5. New York, McGraw-Hill, 2001, p 702.

84 Fenske W, Allolio B: The syndrome of inappropriate secretion of antidiuretic hormone: diagnostic and therapeutic advances. Horm Metab Res 2010;42:691-702.

\title{
Editorial Comment
}

\author{
Meguid El Nahas, Sheffield
}

Esposito and colleagues review the syndrome of inappropriate antidiuresis (SIAD), previously known as syndrome of inappropriate secretion of ADH (SIADH).

Their comprehensive and timely review examines all aspects of physiology and pathophysiology of water retention and dilutional hyponatremia associated with SIAD. They also highlight the potential therapeutic implications and indications of the vaptans; vasopressin receptor antagonists. Vaptans or aquaretics block ADH V2 receptors and decrease aquaporin 2 (AQP2) at renal collecting ducts thus making them insensitive to $\mathrm{ADH}$ and less permeable to water, and thus leading to an increased urinary excretion of free water and correction of hyponatremia. They have so far proved effective in a number of hyponatremic states including those associated with congestive heart failure, cirrhosis and SIAD: SALT-1, SALT-2 and SALTWATER trials. Their side effects include thirst, polyuria, and hypernatremia. I would echo the authors stress on the importance of careful clinical evaluation to distinguish between hypovolemic, euvolemic and hypervolemic causes of hyponatremia. These should not be overlooked before labeling patients as suffering from SIAD and embarking on new and expensive therapies. 